\title{
Perfil bioquímico de algumas enzimas no plasma sangüíneo de potras da raça Brasileiro de Hipismo (BH) criadas em Colina, Estado de São Paulo
}

Fernando José BENESI ${ }^{1}$

Denise Louise HOWARD ${ }^{1}$

Marta Lizandra do Rego

LEAL $^{2}$

Fernando GACEK ${ }^{3}$

José Adalmir Torres de

SOUZA ${ }^{4}$

Wilson Roberto

FERNANDES ${ }^{1}$

\section{Correspondência para:}

Marta L R Leal, Hospital Veterinário, Avenida Roraima, 1000-Cidade Universitária, Bairro Camobi, Santa Maria - RS - 97105-900, mlizandra@smail.ufsm.br.

Recebido para publicação: 12/10/2007 Aprovado para publicação: 12/03/2009

\author{
1 - Departamento de Clínica Médica da Faculdade de Medicina Veterinária e \\ Zootecnia da Universidade de São Paulo, São Paulo-SP \\ 2 - Departamento de Clínica de Grandes Animais da Universidade Federal de \\ Santa Maria, Santa Maria-RS \\ 3 - Instituto de Ciências Biomédicas da Universidade de São Paulo, São Paulo-SP \\ 4 - Departamento de Reprodução da Faculdade de Medicina Veterinária e \\ Zootecnia da Universidade de São Paulo, São Paulo-SP
}

\section{Resumo}

Com o propósito de avaliar o perfil bioquímico de algumas enzimas, em potras sadias da raça $\mathrm{BH}$ (Brasileiro de Hipismo), utilizaram-se 380 amostras de plasma sangüíneo colhidas de 19 animais desde o nascimento até 24 meses de vida. Na análise dos resultados evidenciouse que os valores médios das enzimas FA (fosfatase alcalina) e CK (creatina quinase) foram máximos entre o nascimento e 24 horas de vida (FA-1995.50 UI/ ; CK-189.13UI/L), enquanto que para a LD (lactato desidrogenase) e GGT (gama glutamiltransferase) as maiores magnitudes ocorreram, respectivamente, entre 3 e 4 dias (LD479.11UI/L) e aos 10 dias de idade (GGT-18.70UI/L). As FA, CK, LD e GGT, mostraram diminuições dos valores médios, respectivamente, até 6 meses (FA-323.50UI/L), 20 dias (CK-51UI/ L), 19 meses (LD-214.00UI/L) e 4 meses (GGT-11.40UI/L) estabilizando-se a seguir, com pequenas variações. A atividade da AST (aspartato aminotransferase) que foi mínima logo após o nascimento (AST- 43.38UI/L), aumentou até os sete dias de vida (AST-110.89UI/L), e a seguir diminuiu progressivamente, com pequenas oscilações, até o final do estudo. Todas as enzimas avaliadas sofreram variações influenciadas pelo fator etário, particularmente no período inicial de vida dos animais estudados.

\section{Introdução}

Constituintes bioquímicos e hematológicos variam significativamente nos fluidos orgânicos dos animais desde o nascimento até a idade madura, particularmente ao longo do período neonatal em que profundas modificações fisiológicas estão ocorrendo. A maturidade hepática, por exemplo, possivelmente leva cerca de uma a duas semanas para ocorrer, tal como observado em ratos, ovinos, e nos homens ${ }^{1}$, portanto, ao constatar-se aumentos nas enzimas hepáticas de neonatos, estes não devem ser julgados como uma anormalidade bioquímica, como o que
Palavras-chave:

Bioquímica clínica.

Plasma.

Potras Brasileiro de Hipismo. Enzimas. seriam se fossem comparados com dados publicados na literatura para animais adultos. ${ }^{2}$ $\mathrm{Na}$ prática da clínica eqüina devido às escassas referências para comparação, freqüentemente depara-se com a dificuldade de interpretar os resultados dos exames bioquímicos. O conhecimento destes dados são importantes por permitirem ao clínico delimitar as possíveis doenças suspeitas, confirmar diagnósticos, sugerir prognósticos e avaliar a eficácia da terapia. ${ }^{3} \mathrm{O}$ crescente uso das análises laboratoriais realizadas em hospitais e Clínicas Veterinárias tem despertado a atenção de muitos pesquisadores para a necessidade cada vez maior de se determinar valores de referência, levando-se em 
consideração a idade, a raça, o sexo, e a espécie animal. ${ }^{4}$

Apesar da importância do conhecimento do perfil bioquímico sangüíneo fisiológico nos animais domésticos e embora existam trabalhos internacionais dedicados ao estudo de enzimas no soro e no plasma sanguíneo de eqüinos $1,5,6,7,8,9$ poucas são as pesquisas nacionais relacionadas ao assunto ${ }^{3,10,11}$, especialmente em neonatos, não havendo qualquer estudo em cavalos $\mathrm{BH}$ (Brasileiro de Hipismo). Considerando-se este fato, constituiu-se objetivo deste trabalho estabelecer o perfil bioquímico, no plasma sangüíneo de eqüinos sadios, da raça $\mathrm{BH}$, bem como estudar a influência da evolução etária sobre as enzimas: Fosfatase alcalina (FA) Aspartato aminotransferase (AST), gama glutamiltransferase (GGT), lactato desidrogenase (LD) e creatina quinase (CK).

\section{Material e Método}

Foram utilizadas 19 fêmeas de cavalos BH criadas no Estado de São Paulo, clinicamente sadias, pertencentes à estação experimental de Colina, do Instituto de Zootecnia da Secretária de Agricultura do Estado de São Paulo, das quais foram colhidas 380 amostras de sangue. Os animais considerados foram divididos em dois grupos experimentais, acompanhados por um período de 12 meses, sendo que no primeiro grupo, a avaliação ocorreu desde o nascimento até 12 meses de vida, e no segundo grupo, dos 12 aos 24 meses de vida.

Deste modo, o primeiro grupo foi constituído por 10 fêmeas recém-nascidas avaliadas desde o nascimento, com colheitas de amostras nos tempos: 0-4 horas e entre 12-16 horas pós-nascimento; com, 1, 2, 3, $4,5,6,7,8,9,10,15,20,25,30$, e 45 dias de vida e mensalmente de 2 a 12 meses de idade. As éguas prenhes eram observadas a cada 4 horas aguardando-se o momento do parto, conseqüentemente, ao notar-se um recémnascido, este poderia ter entre 0 e 4 horas de vida. O segundo grupo foi formado a partir de 9 fêmeas que já haviam completado um ano de vida. Neste grupo, as colheitas de sangue foram mensais, sendo realizadas de 12 a 24 meses de vida. Todas as colheitas foram efetuadas às 10 horas da manhã.

As amostras de sangue foram colhidas por punção da veia jugular, com a utilização de tubos de colheita a vácuo siliconizados $\left(\right.$ Vacutainer $^{\circledR}$ ), contendo heparina sódica. Após a colheita, as amostras, devidamente identificadas, foram centrifugadas por cerca de 15 minutos, sendo o plasma sanguíneo separado e armazenado sob congelamento a $-20^{\circ}$ até o momento das análises. Todas as enzimas foram determinadas em analisador bioquímico automático (Bayer Technicon modelo RA 100), segundo os métodos preconizados por

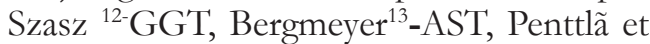
al. ${ }^{14}-\mathrm{FA}$, e Schimid e von Forstner ${ }^{15}$-LD e CK, utilizando-se "Kits comerciais' (Boehringer Manheim). O controle de qualidade era realizado diariamente no aparelho, utilizando-se soros comerciais com valores conhecidos (controle baseado em liofilizado de soro humano): precinorm Unormal (Boehringer - Mannheim) e precipath U-anormal (Boehringer Mannheim). Para calibração do analisador bioquímico automático RA-100 foi utilizado o SET point (Bayer), calibrador químico formulado à base de soro bovino liofilizado, para os sistemas Techinicon RA.

A análise estatística foi realizada considerando-se um experimento inteiramente casualizado no qual testou-se por meio da análise de variância o efeito da idade sobre as variáveis estudadas. Quando a estatística $F$ resultou significativa, verificaram-se os contrastes entre médias com o emprego do teste de Duncan, calculando-se a diferença mínima significativa, e admitindo-se probabilidade de erro de $5 \% .^{16}$ A avaliação estatística foi efetuada utilizando-se do programa computadorizado "Statistical Analysis System"17.

\section{Resultados e Discussão}

Os resultados obtidos para as enzimas, determinadas no plasma sangüíneo 
de eqüinos sadios, da raça $\mathrm{BH}$, criados no Estado de São Paulo, são apresentados nas tabelas 1 e 2.

A atividade da fosfatase alcalina revelou altos valores médios nos primeiros dias pós-nascimento, sendo máximo entre 0 e 4 horas de vida (Tabela 1). A partir de 24 horas de vida ocorreu diminuição significativa, sendo esta progressiva com a evolução etária até os seis meses, quando então os valores mantiveram-se com pequenas oscilações alcançando teores semelhantes àqueles dos animais adultos, concordando este comportamento com aqueles evidenciados por Rumbaugh e Adamson ${ }^{2}$, Bauer et al. ${ }^{5}$, Dumas e Spano, Sato et al. ${ }^{18}$, Gosset e French ${ }^{19}$, Komarek ${ }^{20}$ e Lepage, Marcoux e Tremblay ${ }^{21}$. A elevada atividade da FA, particularmente nos primeiros dias de vida, foi motivo de várias cogitações quanto a sua origem. Vários foram os autores que relacionaram-na com

Tabela 1 - Valores médios de referência (X) e respectivos desvios padrão (S) da atividade da fosfatase alcalina (FAUI/L)e da aspartato aminotransferase (AST-UI/L) no plasma de potras da raça Brasileira de Hipismo com diferentes idades (horas, dias e meses) até dois anos de vida, criadas em Colina - SP

\begin{tabular}{|c|c|c|c|c|c|}
\hline & & \multicolumn{2}{|c|}{ FA (UI/L) } & \multicolumn{2}{|c|}{ AST (UI/L) } \\
\hline Idade & $\mathrm{n}^{\circ}$ & $\mathrm{X}$ & $\mathrm{S}$ & $\mathrm{X}$ & $\mathrm{S}$ \\
\hline $0-4 h$ & 8 & $1995,50^{a}$ & 751,53 & $49,38^{i}$ & 10,90 \\
\hline $12-16 \mathrm{~h}$ & 8 & $1821,25^{a}$ & 706,93 & $71,13^{\mathrm{f}-\mathrm{i}}$ & 16,21 \\
\hline $24 \mathrm{~h}$ & 8 & $1336,88^{b}$ & 738,44 & $79,13^{\mathrm{c}-\mathrm{h}}$ & 28,68 \\
\hline $2 d$ & 9 & 1100,89 bc & 578,78 & $60,56 \mathrm{ch}$ & 17,78 \\
\hline $3 d$ & 9 & $889,22 \mathrm{~cd}$ & 539,79 & $88,44^{\text {a-g }}$ & 19,99 \\
\hline $4 d$ & 9 & $771,78^{d}$ & 469,16 & $86,11^{\text {a-h }}$ & 19,32 \\
\hline $5 d$ & 9 & 638,11 de & 326,32 & $105,56^{a-c}$ & 36,32 \\
\hline $6 \mathrm{~d}$ & 9 & $641,89 \mathrm{de}$ & 358,87 & $104,00^{a-d}$ & 32,83 \\
\hline $7 d$ & 9 & $469,88^{\mathrm{e}}$ & 175,60 & $110,89^{a}$ & 25,47 \\
\hline $8 d$ & 9 & $451,00^{e}$ & 184,92 & $108,00^{a b}$ & 31,22 \\
\hline $9 d$ & 9 & $428,75^{\mathrm{e}}$ & 163,14 & $103,56^{a-d}$ & 34,38 \\
\hline $10 d$ & 10 & $413,00^{e}$ & 162,81 & $105,00^{a-c}$ & 34,58 \\
\hline $15 \mathrm{~d}$ & 10 & $358,00^{e}$ & 191,41 & $97,70^{\text {a-e }}$ & 43,80 \\
\hline $20 d$ & 10 & $357,20^{\mathrm{e}}$ & 173,28 & $89,10^{\mathrm{a}-\mathrm{g}}$ & 36,12 \\
\hline $25 d$ & 10 & $372,90 \mathrm{e}$ & 132,50 & $96,22^{a-c}$ & 32,28 \\
\hline $30 d$ & 10 & $394,80^{e}$ & 110,91 & $92,30^{\mathrm{a}-\mathrm{g}}$ & 20,52 \\
\hline $45 \mathrm{~d}$ & 10 & $380,80^{e}$ & 118,60 & $79,80^{\mathrm{c}-\mathrm{h}}$ & 25,54 \\
\hline $2 \mathrm{~m}$ & 10 & $391,00^{e}$ & 106,86 & $88,50^{a-g}$ & 17,51 \\
\hline $3 \mathrm{~m}$ & 10 & $383,80^{\mathrm{e}}$ & 63,57 & $87,40^{a-h}$ & 14,98 \\
\hline $4 \mathrm{~m}$ & 10 & $368,80^{\mathrm{e}}$ & 68,22 & $90,90^{\mathrm{a}-\mathrm{g}}$ & 15,59 \\
\hline $5 \mathrm{~m}$ & 10 & $361,40^{\mathrm{e}}$ & 71,92 & $90,70^{\mathrm{a}-\mathrm{g}}$ & 11,15 \\
\hline $6 \mathrm{~m}$ & 10 & $323,50^{f}$ & 79,48 & $94,70^{2-\mathrm{g}}$ & 19,90 \\
\hline $7 \mathrm{~m}$ & 10 & $287,20^{f}$ & 61,70 & $98,00^{\text {a-e }}$ & 21,55 \\
\hline $8 \mathrm{~m}$ & 10 & $235,40^{f}$ & 67,80 & $89,50^{a-g}$ & 26,39 \\
\hline $9 \mathrm{~m}$ & 10 & $235,70^{\mathrm{f}}$ & 57,03 & $90,60^{\mathrm{a}-\mathrm{g}}$ & 13,13 \\
\hline $10 \mathrm{~m}$ & 10 & $223,20^{f}$ & 52,84 & $88,80^{\mathrm{a}-\mathrm{g}}$ & 19,36 \\
\hline $11 \mathrm{~m}$ & 10 & $237,60^{f}$ & 69,51 & $93,40^{\text {a-g }}$ & 18,45 \\
\hline $12 \mathrm{~m}$ & 10 & $223,50^{\mathrm{f}}$ & 49,48 & $98,32^{\text {a-e }}$ & 19,79 \\
\hline $13 \mathrm{~m}$ & 10 & $180,00^{\mathrm{f}}$ & 46,71 & $94,13^{\mathrm{a}-\mathrm{g}}$ & 20,73 \\
\hline $14 \mathrm{~m}$ & 10 & $205,22^{f}$ & 45,39 & $94,00^{\mathrm{a}-\mathrm{g}}$ & 19,99 \\
\hline $15 \mathrm{~m}$ & 10 & $208,38^{\mathrm{f}}$ & 51,86 & $77,88^{\mathrm{d}-\mathrm{h}}$ & 14,77 \\
\hline $16 \mathrm{~m}$ & 10 & $177,67^{\mathrm{f}}$ & 44,91 & $77,78^{\mathrm{d}-\mathrm{h}}$ & 11,77 \\
\hline $17 \mathrm{~m}$ & 10 & $177,38^{\mathrm{f}}$ & 33,11 & $73,88^{e-h}$ & 15,67 \\
\hline $18 \mathrm{~m}$ & 10 & $181,88^{\mathrm{f}}$ & 28,38 & $69,00 \mathrm{~g}-\mathrm{i}$ & 7,25 \\
\hline $19 \mathrm{~m}$ & 19 & $176,33^{f}$ & 30,86 & $70,00^{\mathrm{f}-\mathrm{i}}$ & 15,49 \\
\hline $20 \mathrm{~m}$ & 9 & $162,11^{\mathrm{f}}$ & 15,62 & $62,11^{\mathrm{hi}}$ & 9,53 \\
\hline $21 \mathrm{~m}$ & 9 & $187,00^{\mathrm{f}}$ & 47,38 & $81,22^{c-h}$ & 15,94 \\
\hline $22 \mathrm{~m}$ & 9 & $172,56^{f}$ & 31,04 & $84,89^{a-h}$ & 16,00 \\
\hline $23 \mathrm{~m}$ & 9 & $201,33^{f}$ & 37,84 & $93,00^{a-h}$ & 17,77 \\
\hline $24 \mathrm{~m}$ & 9 & $209,00^{f}$ & 51,70 & $92,22^{a-h}$ & 22,66 \\
\hline
\end{tabular}

Letras não coincidentes na vertical acompanhando os valores médios denotam diferença estatística $(\alpha \leq 0,05)$ 
a intensa atividade osteogênica presente durante o desenvolvimento em animais jovens, acreditando que a FA estaria aumentada em concomitância com o crescimento ósseo do animal. ${ }^{8,12,18,21}$ No entanto, no entender de Bauer, Asquith e Kivipelto $^{5}$, o fígado também contribuiria de forma significativa com a alta atividade da FA no potro recém-nascido, sugerindo ainda, que talvez houvesse participação da FA originada dos tecidos intestinais ${ }^{2}$.
Entretanto, Dumas e Spano ${ }^{8}$ demonstraram que nos primeiros seis dias de vida, cerca de $92 \%$ da FA presente no plasma de potros é de origem óssea, sendo o restante de origem hepática, não havendo atividade de FA de origem intestinal até 21 dias de vida. Como a FA é utilizada com freqüência na prática da clínica eqüina, é de extrema importância salientar que nos primeiros seis meses de vida do potro a atividade desta enzima é maior do que os valores encontrados em adultos.

Tabela 2 - Valores médios de referência (X) e respectivos desvios padrão (S) da atividade da gama glutamiltransferase (GGT-UI/L), lactato desidrogenase (LDH-UI/L) e creatina quinase (CK-UI/L) no plasma de potras da raça Brasileira de Hipismo com diferentes idades (horas, dias e meses) até dois anos de vida, criadas em Colina - SP

\begin{tabular}{|c|c|c|c|c|c|c|c|}
\hline & & \multicolumn{2}{|c|}{ GGT (UL/L) } & \multicolumn{2}{|c|}{ LDH (UL/L) } & \multicolumn{2}{|c|}{ CK (UI/L) } \\
\hline Idade & $\mathrm{n}^{\circ}$ & $\mathrm{X}$ & $\mathrm{S}$ & $\mathrm{X}$ & $\mathrm{S}$ & $\mathrm{X}$ & $\mathrm{S}$ \\
\hline $0-4 \mathrm{~h}$ & 8 & $17,75^{\text {a-e }}$ & 4,92 & $352,25^{b-1}$ & 61,21 & $148,57^{b}$ & 37,44 \\
\hline $12-16 \mathrm{~h}$ & 8 & $20,75^{a}$ & 7,13 & $464,88^{\mathrm{ab}}$ & 169,28 & $189,13^{2}$ & 140,27 \\
\hline $24 \mathrm{~h}$ & 8 & $16,25^{a-i}$ & 9,24 & $456,38^{a-c}$ & 143,85 & 113,63 bc & 40,96 \\
\hline $2 d$ & 9 & $16,78^{a-h}$ & 7,31 & $409,44^{a-g}$ & 154,48 & $86,11^{\text {c-e }}$ & 36,58 \\
\hline $3 d$ & 9 & 17,67 a-f & 7,95 & $479,11^{\text {a }}$ & 138,39 & $88,56^{\text {c-e }}$ & 31,17 \\
\hline $4 d$ & 9 & $15,11^{a-k}$ & 9,99 & $431,33^{\text {a-d }}$ & 110,90 & 81,22 c-e & 48,06 \\
\hline $5 d$ & 9 & $18,00^{\text {a-e }}$ & 8,25 & $449,44^{a-c}$ & 73,25 & 60,33 de & 19,46 \\
\hline $6 d$ & 9 & $20,56^{a b}$ & 8,78 & $422,78^{\text {a-f }}$ & 109,74 & 74,89 c-e & 34,00 \\
\hline $7 d$ & 9 & $19,00^{a-c}$ & 6,98 & $425,22^{\mathrm{a}-\mathrm{h}}$ & 169,39 & 96,56 c-e & 54,96 \\
\hline $8 d$ & 9 & $17,22^{\text {a-g }}$ & 66,80 & $445,56^{a-e}$ & 155,83 & 81,44 c-e & 89,25 \\
\hline $9 d$ & 9 & $18,44^{\text {a-d }}$ & 6,35 & $405,67^{\mathrm{a}-\mathrm{g}}$ & 182,43 & 66,67 c-e & 34,23 \\
\hline $10 \mathrm{~d}$ & 10 & $18,70^{a-c}$ & 8,60 & $375,80^{2-i}$ & 112,23 & $60,20 \mathrm{de}$ & 32,55 \\
\hline $15 \mathrm{~d}$ & 10 & $15,40^{a-j}$ & 7,18 & $375,60^{a-i}$ & 141,22 & 76,00 c-e & 77,10 \\
\hline $20 d$ & 10 & $14,90^{\mathrm{b}-\mathrm{k}}$ & 6,42 & $359,30^{b-j}$ & 137,78 & $51,00^{\mathrm{e}}$ & 26,74 \\
\hline $25 \mathrm{~d}$ & 10 & $15,10^{\mathrm{a}-\mathrm{k}}$ & 6,62 & $365,90^{a-i}$ & 119,84 & 59,50 de & 23,22 \\
\hline $30 \mathrm{~d}$ & 10 & $14,00^{c-k}$ & 3,71 & $369,60^{2-i}$ & 128,26 & $55,80^{\mathrm{e}}$ & 36,96 \\
\hline $45 \mathrm{~d}$ & 10 & $13,00^{\mathrm{d}-\mathrm{k}}$ & 5,03 & $376,00^{a-i}$ & 71,98 & $61,00 \mathrm{de}$ & 19,66 \\
\hline $2 \mathrm{~m}$ & 10 & $12,80^{\mathrm{d}-\mathrm{k}}$ & 44,02 & $380,50^{a-g}$ & 106,70 & 57,40 de & 13,84 \\
\hline $3 \mathrm{~m}$ & 10 & $12,80^{\mathrm{d}-\mathrm{k}}$ & 3,12 & $375,30^{a-i}$ & 75,15 & 81,70 c-e & 44,97 \\
\hline $4 \mathrm{~m}$ & 10 & $11,90 \mathrm{~g}-\mathrm{l}$ & 33,67 & $376,10^{a-i}$ & 78,34 & 87,30 c-e & 72,38 \\
\hline $5 \mathrm{~m}$ & 10 & $10,40^{\mathrm{j}-1}$ & 3,24 & $353,10^{b-k}$ & 85,88 & 76,20 c-e & 12,53 \\
\hline $6 \mathrm{~m}$ & 10 & $10,60^{\text {i-l }}$ & 1,90 & $344,60^{d-1}$ & 110,44 & $106,80^{\mathrm{cd}}$ & 76,12 \\
\hline $7 \mathrm{~m}$ & 10 & $9,90^{j-1}$ & 1,85 & $327,90^{\mathrm{d}-\mathrm{m}}$ & 76,97 & $105,40^{\mathrm{cd}}$ & 57,93 \\
\hline $8 m$ & 10 & $10,20^{\mathrm{j}-1}$ & 3,12 & $313,40^{\mathrm{d}-\mathrm{m}}$ & 69,39 & 77,80 c-e & 14,99 \\
\hline $9 \mathrm{~m}$ & 10 & $9,90^{\mathrm{j}-1}$ & 3,11 & 304,30 f-m & 93,17 & 87,00 c-e & 16,48 \\
\hline $10 \mathrm{~m}$ & 10 & $10,50^{\mathrm{i}-1}$ & 22,68 & $310,80^{\mathrm{e}-\mathrm{m}}$ & 78,17 & $73,50^{c-e}$ & 14,32 \\
\hline $11 \mathrm{~m}$ & 10 & $10,60^{i-1}$ & 11,90 & $300,20 \mathrm{~g}-\mathrm{m}$ & 80,22 & $83,10^{c-e}$ & 20,01 \\
\hline $12 \mathrm{~m}$ & 10 & $11,67 \mathrm{~g}-1$ & 2,47 & 270,89 h-m & 81,75 & 80,12 c-e & 18,87 \\
\hline $13 \mathrm{~m}$ & 10 & $12,00^{\mathrm{f}-1}$ & 1,31 & $246,00^{j-m}$ & 83,36 & 64,00 de & 8,57 \\
\hline $14 \mathrm{~m}$ & 10 & $10,89^{\mathrm{i}-1}$ & 2,42 & $291,67 \mathrm{~g}-\mathrm{m}$ & 61,73 & 82,22 c-e & 37,25 \\
\hline $15 \mathrm{~m}$ & 10 & $10,50^{\mathrm{i}-1}$ & 2,33 & $278,33^{\text {h-m }}$ & 43,89 & 67,50 c-e & 28,19 \\
\hline $16 \mathrm{~m}$ & 10 & $9,33 \mathrm{kl}$ & 2,18 & $225,56^{\mathrm{m}}$ & 55,76 & 58,67 de & 18,94 \\
\hline $17 \mathrm{~m}$ & 10 & $11,25^{\mathrm{h}-\mathrm{l}}$ & 1,98 & $233,75 \mathrm{~lm}$ & 56,25 & $53,71^{\mathrm{e}}$ & 19,44 \\
\hline $18 \mathrm{~m}$ & 10 & $9,00^{1}$ & 1,07 & $237,25 \mathrm{k}-\mathrm{m}$ & 68,44 & $52,63^{\mathrm{e}}$ & 14,59 \\
\hline $19 \mathrm{~m}$ & 19 & $8,56^{1}$ & 1,51 & $214,00 \mathrm{~m}$ & 58,02 & $52,78^{\mathrm{e}}$ & 13,41 \\
\hline $20 \mathrm{~m}$ & 9 & $9,44 \mathrm{kl}$ & 1,51 & $220,22 \mathrm{~m}$ & 74,04 & $49,11^{\mathrm{e}}$ & 16,22 \\
\hline $21 \mathrm{~m}$ & 9 & $11,00^{\mathrm{i}-1}$ & 22,87 & $256,67^{\mathrm{i}-\mathrm{m}}$ & 78,84 & $61,44 \mathrm{de}$ & 19,33 \\
\hline $22 \mathrm{~m}$ & 9 & $10,78^{\mathrm{i}-1}$ & 1,39 & $257,56^{\mathrm{i}-\mathrm{m}}$ & 66,67 & 67,56 c-e & 19,18 \\
\hline $23 \mathrm{~m}$ & 9 & $12,44^{e-l}$ & 2,92 & $274,44^{\text {h-m }}$ & 66,64 & 69,78 c-e & 21,40 \\
\hline $24 \mathrm{~m}$ & 9 & $12,00^{\mathrm{f}-\mathrm{l}}$ & 3,74 & $303,33^{f-m}$ & 68,58 & 82,00 c-e & 32,92 \\
\hline
\end{tabular}

Letras não coincidentes na vertical acompanhando os valores médios denotam diferença estatística $(\alpha \leq 0,05)$ 
Consequentemente deve ser utilizada com cautela como indicador de doença hepática ou colestase neste período da vida ${ }^{22}$, uma vez que os resultados desta pesquisa em conjunto com os relatados na literatura 5,8,18,21 indicaram que sua atividade relaciona-se fortemente com a osteogênese.

A atividade plasmática da aspartato aminotransferase variou significativamente sob influência do fator etário, com observação de um valor mínimo entre o nascimento e 4 horas de vida, seguido pelo aumento até os sete dias de idade, quando teve início um decréscimo progressivo dos valores médios até os 20 dias de idade, após o qual a atividade de AST apresentou-se com pequenas variações (Tabela 1). Os valores médios da AST foram inferiores a maioria dos relacionados na literatura. Neste contexto, para justificar-se a disparidade encontrada, deve-se considerar a metodologia empregada, como também o fato das potras consideradas neste estudo serem destinadas à reprodução e, portanto, não serem submetidas a exercícios físicos ou treinamentos constantes. No entanto, em relação à metodologia, Fernandes ${ }^{3} \mathrm{e}$ Rodrigues et al. ${ }^{11}$, realizaram as determinações da AST no mesmo laboratório e com a mesma metodologia usada no presente estudo, obtendo resultados em cavalos criados no Estado de São Paulo, também superiores aos obtidos nas potras $\mathrm{da}$ raça $\mathrm{BH}$, não sendo assim o método usado a explicação para os menores valores de AST. Desta maneira, uma vez que em outras pesquisas foram demonstrados maiores valor desta enzima em animais submetidos a treinamento em relação aos que estavam em repouso, pode ser esta a razão para os valores inferiores obtidos nos eqüinos estudados nesta pesquisa. ${ }^{3,23}$

Maiores valores de AST logo após o nascimento já haviam sido reportados por outros autores. . $^{1,2,18,19,25} \mathrm{O}$ aumento na concentração da AST provocada pelo início da atividade muscular é a explicação mais freqüente na literatura, sendo destacada por Sato, Oda e Kubo. ${ }^{18}$ e Bauer et al. ${ }^{1}$, contrariando a opinião de Patterson e Brown
${ }^{24}$ que atribuíram tal aumento à imaturidade hepática no animal jovem, havendo pesquisadores como Bugalia e $\mathrm{Kumar}^{7}$ que entenderam ser o aumento de ambas as origens. Contudo, não há evidências concretas na literatura para esclarecer esse aumento da AST, é necessário, como foi feito nesta pesquisa, a avaliação conjunta desses resultados com os de enzimas mais específicas para indicar que a origem seja muscular (CK, LD) ou hepática (GGT).

As concentrações de gama glutamiltransferase observadas nas potras desta pesquisa apresentaram valor máximo entre 12 e 16 horas após o nascimento, sendo mantidas com pequenas oscilações até cerca de 10 dias de vida, quando diminuíram, progressivamente, de forma significativa a partir de quatro meses de idade, seguindo então com tendência à estabilização até 24 meses de vida (Tabela 2). Na literatura consultada, Bauer, Asquith e Kivipelto ${ }^{5}$, Gosset e French ${ }^{19}$, Patterson e Brown ${ }^{24}$ e Ximenes et al. ${ }^{26}$ encontraram comportamento dos valores médios da GGT semelhantes àqueles obtidos no presente estudo, ou seja, elevados até cerca de 15 dias de idade, e, que após este período, sofreram diminuição progressiva. A ausência do completo desenvolvimento hepático durante os primeiros dias de vida do potro parece ser a causa deste aumento. ${ }^{5,24,25}$ Por outro lado é interessante comentar que em potros não ocorre um aumento significativo da GGT em conseqüência da ingestão de colostro, como acontece em bezerros neonatos. ${ }^{24}$ As magnitudes dos valores médios observados no presente estudo são relativamente inferiores à maioria daquelas descritas na literatura revisada. ${ }^{5,19,24,26}$ No entanto, estão de acordo com os apresentados por Bauer et al. ${ }^{1}$. Em contraposição, as atividades médias obtidas foram maiores do que aquelas descritas por Rodrigues et al. ${ }^{11} \mathrm{em}$ cavalos da raça Mangalarga Paulista, sendo, todavia, similares aos apresentados por Fernandes ${ }^{3} \mathrm{em}$ animais adultos utilizados em enduro, determinadas nas mesmas condições que a presente pesquisa, indicando, pois, que a causa dessas 
variações não estaria relacionada à metodologia empregada.

A concentração de lactato desidrogenase (LD) apresentou aumento a partir de 12 horas após o nascimento, sendo este significante até os quatro meses de vida, passando a diminuir progressivamente com oscilações até os 19 meses vida, quando apresentou valor mínimo (Tabela 2). Deste momento até os 24 meses de vida registrouse nova tendência de aumento dos valores, que concordou com as observações de Rumbaugh e Adamson ${ }^{2}$ e Sato, Oda e Kubo. ${ }^{18}$ Nenhuns dos autores consultados na literatura comentaram a respeito da possível causa do aumento desta enzima observado no animal jovem. No entanto, deve-se ressaltar que a LD está presente em diversos tecidos, inclusive nos tecidos muscular esquelético, cardíaco e hepático ${ }^{6}$, tendo comportamento que se correlaciona bem com os resultados obtidos para a AST e CK na detecção da lesão muscular, como afirmado por Reed e Andrews ${ }^{22}$.

Considerando-se as curvas de variação de atividade das enzimas AST, CK, LD e GGT nos primeiros sete dias pósnascimento das potras estudadas nesta pesquisa (Tabelas 1 e 2) pode-se afirmar que nas primeiras 24 horas de vida a AST refletiu um provável efeito de atividade de origem muscular e hepática, tendo em vista que a GGT e a CK apresentaram seus valores máximos. A seguir ocorreu diminuição dos valores da $\mathrm{CK}$, tendo concentrações com comportamento similar aos das enzimas LD e GGT, com curvas que acompanharam aquela das concentrações de AST, que atingiram valor máximo aos sete dias de vida. Esta constatação sugere fortemente que a partir de 2 dias de vida, as variações da AST e LD tiveram origem hepática.

A tendência a aumento da $\mathrm{LD}$ a partir dos 20 meses até os 24 meses de vida (Tabela 2) foi similar à relatada por Ximenes et al. ${ }^{26}$, que observaram, aumentos da LD que evoluíram com o avançar da idade, ao avaliarem os animais a partir dos oito meses de vida. Considerando-se comparativamente as magnitudes dos valores obtidos, independentemente $\mathrm{da}$ metodologia utilizada, verificou-se que foram semelhantes àqueles apresentados por Rumbaugh $\mathrm{e}$ Adamson ${ }^{2} \mathrm{em}$ animais do nascimento até 48 horas de vida, e aos reportados por Fernandes ${ }^{3}$ para cavalos adultos, diferindo, todavia, daqueles apresentados pelos demais autores ${ }^{18,26,27}$.

A atividade $d a$ creatina quinase apresentou aumento significante entre $12 \mathrm{e}$ 16 horas de vida, atingindo valor máximo, seguido por diminuição até os dois dias de idade, quando houve tendência à estabilização da atividade, porém, com pequenas variações em alguns períodos (Tabela 2). Deve ser ressaltada ainda, a grande variação entre os indivíduos avaliados, observada em alguns momentos da avaliação e caracterizada por altos valores obtidos para os desvios padrão. Como a CK é uma enzima cuja maior fonte é a musculatura, considera-se uma boa indicadora de lesão muscular ${ }^{25}$ acreditandose que seu aumento no recém-nascido, esteja relacionado com o início e aumento da atividade muscular ${ }^{28}$ ou talvez, ao traumatismo muscular sofrido com o parto $^{25}$. Com relação às maiores concentrações de CK observadas logo após o nascimento, somente Ricketes ${ }^{28}$ fez semelhante constatação. No entanto, após a primeira semana de vida, as oscilações das concentrações da CK observadas no presente estudo também ocorreram como nos resultados obtidos por Blackmore e Elton $^{23}$, podendo-se considerar que tal fato decorreu da exercitação natural das potras, uma vez que não foram submetidas a qualquer treinamento em especial.

Os valores médios da CK obtidos nas diferentes faixas etárias foram semelhantes àqueles relatados para fêmeas adultas por Kitchen e Rossdale ${ }^{29}$, diferindo das concentrações registradas por Blackmore e Elton $^{23}$ e Ricketes ${ }^{28}$. Em relação aos valores descritos por Fernandes ${ }^{3}$, os observados nesta presente pesquisa foram menores, provavelmente por considerar este autor, somente eqüinos condicionados à realização de exercícios prolongados e extenuantes 
(provas de enduro) o que no entender de Blackmore e Elton ${ }^{23}$ e Stockham ${ }^{30}$ poderia ser a razão dos maiores valores da CK.

\section{Conclusões}

Todas as enzimas avaliadas sofreram variações influenciadas pelo fator etário, particularmente nas primeiras semanas de vida dos animais estudados. As curvas de atividade das enzimas analisadas (AST, CK, LD, e GGT) refletem as exigências funcionais a que são submetidos os neonatos imediatamente após o nascimento. Particularmente a AST nas primeiras 24 horas de vida, refletiu efeito de origem muscular e hepática e a partir do segundo dia de idade, a semelhança da LD, somente variações de origem hepática.

\section{Biochemical profile of some plasmatic enzymes in BH (Brasileiro de Hipismo) filies bred Colina in São Paulo State}

\section{Abstract}

380 plasma samples were used with the purpose of evaluate the biochemical profile of some enzymes in healthy BH (Brasileiro de Hipismo) fillies. These samples were collected from 19 animals since birth until 24 months of age. The results showed that the mean values of ALP (alkaline phosphatase) and CK (creatine kinase) were higher between birth and 24 hours of life (FA-1995.50 UI/; CK189.13UI/L),

whereas for LD (lactate dehidrogenase) and GGT (gama glutamiltransferase) the highest values were, respectively, between 3 and 4 days (LD-479.11UI/L) and with 10 days of life (GGT-18.70UI/ L). AP, CK, LD and GGT showed a reduction of the mean values, respectively, until 6 months (FA-323.50UI/L), 20 days (CK-51UI/ L), 19 months (LD-214.00 UI/L) and 4 months (GGT-11.40UI/L) stabilizing with some oscillations. The activity of AST (aspartate aminotransferase) was minimal after birth (AST- 43.38UI/L) increased until the seventh day of life (AST-110.89UI/L) and next it diminished progressively with little oscillations until the end of the study. All enzymes evaluated were influenced by age, particularly in the initial period of life of the animals studied.

\section{Referências}

1 BAUER, J. E.; HARVEY, J. W.; ASQUITH, R. L.; MCNULTY, P. K.; KIVIPELTO, J. Clinical chemistry reference values of foals during the first year of life. Equine Veterinary Journal, v. 16, n. 4, p. 361-363, 1984.

2 RUMBAUGH, C. E.; ADAMSON, P. J. W. Automated serum chemical analysis in the foal. Journal American Veterinary Medical Association, v. 183, n. 7, p. 769772, 1983.

3 FERNANDES, W. R. Alterações dos parâmetros do eletrocardiograma e da crase sangüínea em eqüinos das raças Arabe e Mangalarga, bem como de mestiços, submetidos à prova de enduro, 1994. $73 \mathrm{f}$. Tese (Doutorado) - Faculdade de Medicina Veterinária e Zootecnia, Universidade de São Paulo, São Paulo, 1994.

4 TASKER, J. B. Fluid and electrolyte studies in the
Key words:

Biochemical values.

Plasma.

Brasileiro de Hipismo horses. Enzymes. horse. I. Blood values in 100 normal horses. Cornell Veterinary, v. 68, n. 4, p. 480-505, 1978.

5 BAUER, J. E.; ASQUITH, R. L.; KIVIPELTO, J. Serum biochemical indicators of liver function in neonatal foal. American Journal Veterinary Research, v. 50, n. 12, p. 2037-2041, 1989.

6 BOYD, J. W. The mechanisms relating to increases in plasma enzymes and isoenzymes in diseases of animals. Veterinary Clinical Pathology, v. 12, n. 2, p. 9-24, 1983.

7 BUGALIA, N. S.; KUMAR, D. Levels of biochemical, mineral and enzyme constituents in blood of male foals (Equus caballus). Indian Veterinary Journal, v. 73, p. 633-636, 1996.

8 DUMAS, M. B.; SPANO, J. S. Characterization of equine alkaline phosphatase isoenzymes based on their electrophoretic mobility by polyacrylamide gel disc electrophoresis. American Journal Veterinary Research, v. 41 , n. 12 , p. $2076-2081,1980$. 
9 SICILIANO, P. D.; LAWRENCE, L. M.; DANIELSEN, K.; POWELL, D. M.; THOMPSON, K. N. Effect of conditioning and exercise type on serum creatine kinase and aspartate aminotransferase activity. Equine Veterinary Journal, v. 18, p. 243-247, 1995. Supplement.

10 CAMARA E SILVA, I. A.; SOTO-BLANCO, B. Determinação das atividades séricas de creatinina quinase, lactato desidrogenase e aspartato aminotransferase em eqüinos de diferentes categorias de atividade. Arquivos Brasileiro de Medicina Veterinária e Zootecnia, v. 59, n. 1, p. 250-252, 2007.

11 RODRIGUES, M. N. S.; NORONHA, T. A.; SOUZA, P. M.; MIRANDOLA, R. M. S.; LEAL, M. L. R.; FERNANDES, W. R.; BENESI, F. J. Influência do sexo e da idade nos valores séricos das bilirrubinas, AST e GGT de cavalos da raça Mangalarga. ARS Veterinária, v. 22, n. 2, p. 103-111, 2006.

12 SZASZ, G. A kinetic photometric method for serum gamma-glutamyltranspeptidase. Clnical Chemistry, v. 15, n. 2, p. 124-135, 1969.

13 BERGMEYER, H. U. Methoden der enzymatischen analyse. 3. ed. Aufl. Weirhein,: Verlag Chemie, 1974. p. 769.

14 PENTTILÃ, I. M.; JOKELA, H. A.; VIITALA, A. J.; HEIKKINEN, E.; NUMMI, S.; PYSTYNEN, P. Activities of aspartato and alaninoaminotransferase and alkaline phosphatase in sera of healthy subjects. Scandinavian Journal Clinical Laboratory Investigation, v. 35, p. 275, 1975.

15 SCHIMID, M.; VON FORSTNER, M. Laboratório testing in the veterinary medicine and clinical monitoring, Boehringer Mannhein, 1986. 235 p.

16 BERQUÓ, E. S.; SOUZA, J. M. P.; GOTLIEB, S. L. D. Bioestatística. São Paulo: EPU, 1980. 325 p.

17 STATISTICAL ANALISYS SYSTEM. SAS user's guide: statistics. Cary: SAS Institute, 1985. 956 p.

18 SATO, T.; ODA, K.; KUBO, M. Hematological and biochemical values of throughbred foals in the first six months of life. Cornell Veterinary, v. 69, n. 1, p. 3-19, 1979.

19 GOSSET, K. A.; FRENCH, D. D. Effect of age on liver enzyme activities in serum of healthy quarter horses. American Journal Veterinary Research, v. 45, n. 2, p. 354-356, 1984.

20 KOMAREC, J. Biochemical reference values of the blood of foals and their significance in monitoring their health. Veterinarstvi, v. 36, n. 11, p. 502-504, 1986.

21 LEPAGE, O. M.; MARCOUX, M.; TREMBLAY, A. Serum osteocalcin or bone Glaprotein, a biochemical marker for bone metabolism in horses: differences in serum levels with age. Canadian Journal Veterinary Research, v. 54, p. 223-226, 1990.

22 REED, S. M.; ANDREWS, F. M. The biochemical evaluation of liver function in the horses. Proceedings American Association of Equine Practioners, v. 1, p. 81-93, 1987.

23 BLACKMORE, D. J; ELTON, D. Enzyme activity in the serum of thoroughbred horses in the United Kingdom. Equine Veterinary Journal, v. 7, n. 1, p. 3439, 1975.

24 PATTERSON, W. H; BROWN, C. M. Increase of serum gamma-glutamyltransferase in neonatal standardbred foals. American Journal Veterinary Research, v. 47, n. 11, p. 2461-2463, 1986.

25 BERNARD, W. V.; REIMER, J. M. Examination of the foal. Veterinary Clinical of North American: Equine Practice. Perinatology, v. 10, n. 1, p. 37-67, 1994.

26 XIMENES, L. A. et al. Indagine su costanti ematochimiche di equine Anglo-Arabo-Sarde. La Clinica Veterinária, v. 107, p. 50-51, 1984.

27 LEANDON, D. P. Clinical pathology data. In: ROBINSON, N. E. Current therapy in equine medicine, v. 3, 1992. p. 822-825.

28 RICKETTS, S. W. The laboratory as an aid to clinical diagnosis. Veterinary Clinical of North American: Equine Practice, v. 3, p. 445-460, 1987.

29 KITCHEN, H.; ROSSDALE, P. D. Metabolic profiles of newborn foals. Journal of Reproduction and Fertility, Supplement, v. 23, n. 3, p. 705-707, 1975.

30 STOCKHAM. S. Interpretation of equine serum biochemical profile results. Veterinary Clinical of North American: Equine Practice, v. 11, n. 3, p. 391-414, 1995. 